\title{
Association between exercise-induced pulmonary hemorrhage and inflammatory airway disease in polo ponies
}

\author{
Katia Moreira da SILVA ${ }^{1 *}$, Juliana Nabuco Pereira OTAKA ${ }^{1}$, \\ Carlos Alexandre Paula GONÇALVES ${ }^{1}$, Estevão Grossi Aguiar SILVA ${ }^{1}$, \\ Nayro Xavier de ALENGAR ${ }^{1}$ and Daniel Augusto Barroso LESSA ${ }^{1}$ \\ ${ }^{1}$ Federal Fluminense University, Rio de Janeiro 24.230-340, Brazil
}

The respiratory system is essential for health and high athletic performance in horses. Respiratory diseases have been recognized as having a major impact on training equine animals and are commonly cited as the second most common cause of wasted training time. Inflammatory airway disease (IAD) is an important cause of poor performance in young racehorses. Exercise-induced pulmonary hemorrhage (EIPH) is considered a major issue for the equine industry because of its high prevalence and association with reduced athletic performance. In Brazil, polo is a growing equestrian sport, but studies on it are still scarce. The aim of this study was to evaluate the occurrence of EIPH, the association between EIPH and IAD, and EIPH influence on the tracheal cytological profile of polo ponies. Thirty-seven horses regularly used for polo were included in this study. Endoscopic examination was performed every 30 to 90 min after practice, and tracheal lavage was performed after 18 to $24 \mathrm{hr}$. Sixteen animals (43.2\%) presented a score of 0 for mucus in endoscopy; twelve animals (32.4\%) presented a score for 1 and nine animals (24.3\%) presented score 2 of mucus. IAD was characterized by tracheal cytology in 12 animals (32.4\%). The occurrence of EIPH in this study was 29.7\% (11/37). No significant difference was found in the cell types in tracheal cytology when EIPH-positive and EIPH-negative horses were compared. Polo ponies are affected by IAD and EIPH in relevant proportions, but there was no association between EIPH and tracheal cytological profile.

Key words: EIPH, IAD, neutrophils, tracheal wash

\author{
J. Equine Sci. \\ Vol. 28, No. 2 \\ pp. 55-59, 2017
}

Respiratory diseases are one of the major causes of low performance and economic losses in the equine industry. Despite the growth in the number of animals used for polo activity and the reported high frequency of respiratory diseases in other activities [2, 4, 24, 36], horses used for polo have been poorly studied in clinical and epidemiological studies.

Inflammatory airway disease (IAD) can be defined as a failure in the regulation of inflammatory cell homeostasis in the airways and presents variable clinical signs $[6,9]$. Animals with IAD usually do not show clear signs of respi-

Received: January 4, 2017

Accepted: April 21, 2017

*Corresponding author. e-mail: katiamoreiras@yahoo.com.br C2017 Japanese Society of Equine Science

This is an open-access article distributed under the terms of the Creative Commons Attribution Non-Commercial No Derivatives (by-nc-nd) License. (CC-BY-NC-ND 4.0: https://creativecommons.org/licenses/ by-nc-nd/4.0/) ratory or systemic disease but instead show discrete and variable degree of airway inflammation [29]. IAD has been described in animals used for various activities, such as race horses [5, 18, 33] and horses used for policing [19]. For IAD diagnosis, collection of respiratory secretions is considered very important $[11,14]$. Although bronchoalveolar lavage (BAL) is the adopted method for collection of respiratory secretions [9], it requires the animal to rest for at least $24 \mathrm{hr}$ afterward [16], which makes the procedure unfeasible for sporting animals. It has been suggested that the presence of tracheal inflammation may not be sufficient to characterize IAD due to the lack of correlation between TW (tracheal wash) and BAL cytology $[8,29]$. However, the term IAD has already been used to describe the inflammation based on the presence of increased neutrophils in the tracheal lavage of racehorses. [18, 36].

Exercise-induced pulmonary hemorrhage (EIPH) refers to the presence of pulmonary blood in the airways after intense exercise $[7,26]$. Its prevalence varies according to 
the exercise intensity and diagnosis method. In racehorses, the occurrence of EIPH varies from 15 to $75 \%[3,7,33]$ and can reach $90 \%$ of animals [21]. In polo ponies, prevalences of $46 \%$ [25] and $34.09 \%$ [27] have been reported.

Studies have been carried out to investigate the causeeffect relationship between IAD and EIPH [22], and they describe two mechanisms: inflammation (and consequently bronchoconstriction), which increases intrapleural pressure and leads to bleeding, and the presence of blood in the alveoli and interstitial spaces, which may lead to inflammation and fibrosis [32]. However, EIPH can occur regardless of whether or not the pulmonary inflammation is present $[34,35]$. The association between EIPH and airway inflammation has been studied in race animals $[1,12,15,26]$ but the results remain controversial. However, to the best of our knonledge, there are currently no descriptions of an association between EIPH and IAD in polo ponies.

The aim of this study was to evaluate the occurrence of EIPH, the association between EIPH and IAD, and the influence of EIPH on the tracheal cytological profile of polo ponies.

\section{Materials and Methods}

This study was approved by the Committee for Animal Experimentation of Fluminense Federal University (study number 0068-08).

\section{Methods}

We studied 37 horses ( 21 females and 16 males between 3 and 22 years old and weighting between 380 and $480 \mathrm{~kg}$ ) regularly used for polo practice in the city of Rio de Janeiro, Brazil. The animals were fed commercial food, oat and alfafa hay, and supplemented with mineral salt. All animals were kept in stables of $12 \mathrm{~m}^{2}$, and under the same bedding conditions. The horses were periodically vaccinated against tetanus, influenza, eastern and western encephalomyelitis, and rabies. All the animals had engaged in regular physical activity, with no physical complaints or signs of apparent disease. No horse was under any treatment or drug effect during the study.

Polo matches last roughly $2 \mathrm{hr}$ and are divided into periods called "chukkas" [31]. Each chukka has a duration of 7.5-min, and there is a 3-min interval is between them. All the horses in this study took part for just one period, twice a week. On other days of the week, only light exercises were performed.

An endoscopic evaluation of the respiratory tract was performed between 30 and 90 min after the end of each chukka [28]. The presence of blood and tracheal mucus was scored [7, 13]

TW was collected 12 to $16 \mathrm{hr}$ post exercise as previously described [37]. TW samples were centrifuged at $110 \mathrm{~g}$ for 5 min (model 206R; Fanem, São Paulo, SP, Brazil). Cell pellets were used to prepare slides with the linear smear technique [38]. Smears were fixed in methanol and stained with Giemsa. A differential cell count was obtained by analyzing 300 cells/slide from direct smears, and then mean values were calculated.

Horses with TW containing neutrophils counts $<20 \%$ and eosinophil counts $<1 \%$ were considered healthy, and those with neutrophil counts $\geq 20 \%$ and/or eosinophil counts $\geq 1 \%$ were considered to have an inflammatory profile [29]. We assigned the term IAD positive to these animals [18].

Statistical analysis was performed using the IBM SPSS Statistics for Windows software. A Kolmogorov-Smirnov test was used to evaluate data distribution. The cell type quantities of EIPH-positive and EIPH-negative groups were compared by Mann-Whitney test, with the significance level set at $5 \%$.

\section{Results}

\section{Endoscopic examination}

Sixteen animals (43.2\%) presented a score of 0 for mucus in endoscopy; twelve animals $(32.4 \%)$ presented a score of 1 for mucus and nine animals $(24.3 \%)$ presented a score of 2 for mucus. No mucus rated above a score of 2 was observed.

Endoscopic evidence of EIPH was found in 11 animals (29.7\%). Seven animals had an EIPH score of 1, one animal had an EIPH score of 2, and two animals had an EIPH score of 3 .

\section{Tracheal cytology}

Twelve (32.4\%) animals had IAD characterized by increased neutrophils and/or eosinophils. Nine (24.3\%) presented neutrophilia in tracheal citology and three (8.1\%) presented eosinophilia. The mean percentages and standard deviations for the differential counts of healthy and IAD animals are shown in Table 1.

No significant difference was detected between the cell types found in the tracheal wash when comparing EIPHpositive and EIPH-negative animals. The mean cell counts and their standard deviations are shown in Table 2.

\section{Discussion}

The occurrence of IAD in this study was similar to the reported occurrence in horses in military use [30] and lower than that observed in racehorses $[9,36]$. Two factors that must be considered are the time period in which the endoscopic examination occurred (at rest or post exercise) and the subjectivity of the observer.

IAD occurrence was also similar to that reported for 
Table 1. Mean percentages and standard deviations for differential cell counts in TW of polo ponies

\begin{tabular}{lccccc}
\hline \multicolumn{1}{c}{$\mathrm{n}=37$} & Neutrophils & Lymphocytes & Macrophages & Eosinophils & Epithelial cells \\
\hline Healthy $(\mathrm{n}=25)$ & $7.39 \pm 6.31$ & $7.80 \pm 7.28$ & $36.63 \pm 22.59$ & $0.36 \pm 0.76$ & $47.68 \pm 29.48$ \\
IAD $(\mathrm{n}=12)$ & $57.76 \pm 28.82$ & $4.36 \pm 1.95$ & $24.71 \pm 20.01$ & $0.1 \pm 0.21$ & $13.03 \pm 18.05$ \\
\hline
\end{tabular}

Table 2. Mean percentages and standard deviations for cell counts in TW of EIPH-positive and EIPH-negative polo ponies

\begin{tabular}{lccccc}
\hline \multicolumn{1}{c}{ n=37 } & Neutrophils & Lymphocytes & Macrophages & Eosinophils & Epithelial cells \\
& $P=0.431$ & $P=0.743$ & $P=0.418$ & $P=0.183$ & $P=0.540$ \\
\hline No EIPH $(\mathrm{n}=26)$ & $19.26 \pm 24.61^{\mathrm{a}}$ & $7.71 \pm 7.35^{\mathrm{a}}$ & $31.05 \pm 19.25^{\mathrm{a}}$ & $0.26 \pm 0.64^{\mathrm{a}}$ & $41.6 \pm 29.71^{\mathrm{a}}$ \\
EIPH $(\mathrm{n}=11)$ & $20.50 \pm 31.36^{\mathrm{a}}$ & $5.16 \pm 3.76^{\mathrm{a}}$ & $40.05 \pm 28.41^{\mathrm{a}}$ & $0.38 \pm 0.77^{\mathrm{a}}$ & $33.7 \pm 34.18^{\mathrm{a}}$ \\
\hline
\end{tabular}

Results are expressed as the mean \pm standard deviation (SD). Same letters in the columns indicate no statistically significant differences (Mann-Whitney, $P<0.05$ ).

army horses [20] and lower than that reported animals in training [1] or used in policing [17]. In racehorses with a history of poor performance, IAD occurrence was higher [18]. Young horses in training often present posterior airways inflammation characterized by cytological evidence in tracheobronchial aspirates [32].

Bronchoalveolar lavage is the chosen method for IAD diagnosis [9]. However, it is important to consider the difficulty of performing this procedure in animals used for sporting activities due to the time period needed for rest and sedation. In these cases, tracheal lavage should be recommended. The term IAD was previously used for animals classified with neutrophilic infiltration in tracheal lavage [18]. We believe that in some situations, the term IAD can and should be employed. All animals in our study had no clinical complaints and had engaged in regular physical activity. Therefore, the proportion of airway inflammation should be considered important. Tracheal lavage was determinant for IAD diagnosis, taking into account the fact that mucus scoring at endoscopy is subject to variation for several reasons such as the time period after exercise and observer interpretation.

Endoscopic evidence of EIPH was found in 11 animals (29.7\%). The occurrence of EIPH in polo animals was similar to that reported previously in the same population [27]. These authors did not observe a statistically significant relationship among animals with tracheal secretion and with EIPH. The occurrence of EIPH in our study is also lower than observed in Chile [25] and higher than that observed in Brazil [20] in polo ponies.

\section{Cytological profiles of EIPH horses}

The differential cell counts of EIPH-positive and EIPHnegative animals showed no statistical difference. These findings are similar to those of previous studies $[1,4,5]$. Other studies suggest that IAD may be important for EIPH evolution, but this does not mean inflammation is a prerequisite for EIPH [22].

An increase in neutrophil counts for EIPH-positive animals was also found [12, 14, 23]. This result may vary due to differences in the tracheal lavage collection period after the exercise, as well as the place where the procedure was performed. In our study, the period between bleeding and lavage collection was between 12 and16 hr in length, and this may not have been enough to detect a local inflammatory response. It is known that the inflammatory response caused by previous episodes of EIPH has an important role in new and more intense bleeding episodes, especially if horses undergo intense exercise within 3 to 7 days after the first episode of bleeding [22]. An association between EIPH and inflammation has also been demonstrated, and it was demonstrated that previous hemorrhage within a period of one month was a major risk factor for EIPH [26]. The time interval for performing diagnostic tests and the nature of the exercise performed, are factors that should be considered in the study's design. Other studies suggested that standardization of time and characterization of IAD phenotypes are critical parameters for studies of equine lung diseases [9].

Regarding procedural variations, tracheal lavage provides a pool of samples from both lungs, the distal trachea and bronchi. On the other hand, BAL allows for collection directly from the lung site involved in bleeding (caudal lobe) [10]. Thus, TW represents a more diluted sample when compared with BAL. These differences could influence the variability of results among studies. More information about IAD and EIPH pathophysiology is still needed to improve knowledge about possible interactions between these diseases [8]. Our results do not allow us to demonstrate the influence of EIPH on IAD. It should be considered that the etiology of EIPH is related to pulmonary capillary stress and failure and not necessarily related to pulmonary inflammation [32]. 
It has been demonstrated that polo ponies presented IAD and EIPH in important proportions, even when apparently healthy or physically active. These respiratory diseases should be considered in the physical state evaluation of athlete animals. No significant differences were found in the cytological profiles of tracheal lavage, regardless the presence of EIPH. Thus, there was no influence of EIPH on the cytological profile of tracheal lavage or IAD.

\section{Conflict of Interest}

None of the authors of this paper has a financial or personal relationship with other people or organizations that could inappropriately influence or bias the content of the paper.

\section{References}

1. Allen, K.J., Tremaine, W.H., and Franklin, S.H. 2006. Prevalence of inflammatory airway disease in national hunt horses referred for investigation of poor athletic performance. Equine Vet. J. Suppl. 38: 529-534. [Medline] [CrossRef]

2. Burrell, M.H., Wood, J.L., Whitwell, K.E., Chanter, N., Mackintosh, M.E., and Mumford, J.A. 1996. Respiratory disease in thoroughbred horses in training: the relationships between disease and viruses, bacteria and environment. Vet. Rec. 139: 308-313. [Medline] [CrossRef]

3. Burrell, M.H. 1985. Endoscopic and virological observations on respiratory disease in a group of young Thoroughbred horses in training. Equine Vet. J. 17: 99-103. [Medline] [CrossRef]

4. Chapman, P.S., Green, C., Main, J.P., Taylor, P.M., Cunningham, F.M., Cook, A.J., and Marr, C.M. 2000. Retrospective study of the relationships between age, inflammation and the isolation of bacteria from the lower respiratory tract of thoroughbred horses. Vet. Rec. 146: 91-95. [Medline] [CrossRef]

5. Christley, R.M., Hodgson, D.R., Rose, R.J., Wood, J.L., Reids, S.W., Whitear, K.G., and Hodgson, J.L. 2001A. A case-control study of respiratory disease in Thoroughbred racehorses in Sydney, Australia. Equine Vet. J. 33: 256-264. [Medline] [CrossRef]

6. Costa, L.R.R., Seahorn, T.L., Moore, R.M., Taylor, H.W., Gaunt, S.D., and Beadle, R.E. 2000. Correlation of clinical score, intrapleural pressure, cytologic findings of bronchoalveolar fluid, and histopathologic lesions of pulmonary tissue in horses with summer pasture-associated obstructive pulmonary disease. Am. J. Vet. Res. 61: 167-173. [Medline] [CrossRef]

7. Costa, M.F.M., Thomassian, A., and Gomes, T.S. 2004. Study of exercise induced pulmonary haemorrhage (EIPH) in flat racing Thoroughbred horses. R. Bras. Cien. Vet. 11: 89-91 [in Portuguese].
8. Couëtil, L.L., Hoffman, A.M., Hodgson, J., BuechnerMaxwell, V., Viel, L., Wood, J.L.N., and Lavoie, J.P. 2007. Inflammatory airway disease of horses. J. Vet. Intern. Med. 21: 356-361. [Medline] [CrossRef]

9. Couëtil, L.L., Cardwell, J.M., Gerber, V., Lavoie, J.P., Léguillette, R., and Richard, E.A. 2016. Inflammatory airway disease of horses-Revised Consensus Statement. J. Vet. Intern. Med. 30: 503-515. [Medline] [CrossRef]

10. Derksen, F.J., Brown, C.M., Sonea, I., Darien, B.J., and Robinson, N.E. 1989. Comparison of transtracheal aspirate and bronchoalveolar lavage cytology in 50 horses with chronic lung disease. Equine Vet. J. 21: 23-26. [Medline] [CrossRef]

11. Dixon, P.M., Railton, D.I., and McGorum, B.C.I. 1995. Equine pulmonary disease: a case control study of 300 referred cases. Part 3: Ancillary diagnostic findings. Equine Vet. J. 27: 428-435. [Medline] [CrossRef]

12. Doucet, M.Y., and Viel, L. 2002. Clinical, radiographic, endoscopic, bronchoalveolar lavage and lung biopsy findings in horses with exercise-induced pulmonary hemorrhage. Can. Vet. J. 43: 195-202. [Medline]

13. Gerber, V., Straub, R., Marti, E., Hauptman, J., Herholz, C., King, M., Imhof, A., Tahon, L., and Robinson, N.E. 2004. Endoscopic scoring of mucus quantity and quality: observer and horse variance and relationship to inflammation, mucus viscoelasticity and volume. Equine Vet. J. 36: 576-582. [Medline] [CrossRef]

14. Hegedüs, R.M., Michima, L.E.S., Souza, V.R.C., Dutra, G.H.P., Fernandes, W.R., and Coelho, C.S. 2007. Evaluation of tracheal wash of horses with exercise-induced pulmonary hemorrhage treated with furosemide. Arq. Bras. Med. Vet. Zootec. 59: 527-529. [CrossRef]

15. Hodgson, J.L., and Hodgson, D.R. 2002. Inflammatory airway disease. In: Lekeux, P. Equine respiratory disease. http://www.ivis.org/special_books/lekeux/hodgson/chapter_frm.asp?LA=1 (accessed September 9, 2016).

16. Hoffman, A.M. 2008. Bronchoalveolar lavage: sampling technique and guidelines for cytologic preparation and interpretation. Vet. Clin. North Am. Equine Pract. 24: 423-435, vii-viii. [Medline] [CrossRef]

17. Jorge, M.L.L.A., Viscardi, V., Silva, K.M., Otaka, J.N.P., Alencar, N.X., Torres-Filho, R.A., and Lessa, D.A.B. 2014. Alkaline phosphatase activity in bronchoalveolar lavage of police horses in Rio de Janeiro State, Brazil. Cienc. Rural 44: 92-96 (in Portuguese). [CrossRef]

18. Kusano, K., Ishikawa, Y., Seki, K., and Kusunose, R. 2008. Characteristic of inflammatory airway disease in Japanese thoroughbred racehorses. J. Equine Sci. 19: 25-29. [Medline] [CrossRef]

19. Lessa, D.A.B., Jorge, M.L.L.A., Viana, E.B., Alencar, N.X., and Fernandes, W.R. 2011. Evaluation of bronchoalveolar fluid of horses with inflammatory airway disease. Braz. J. Vet. Res. Anim. Sci. 48: 123-130. [CrossRef]

20. Lessa, D.A.B., Machado, C.H., Duarte, C.S., Wachholz, 
L., Lima, J.R.P.A., and Fernandes, W.R. 2005. Lower respiratory tract diseases in riding horses in Rio de Janeiro. Rev. Bras. Cien. Vet. 12: 77-83 (in Portuguese).

21. McKane, S.A., Canfield, P.J., and Rose, R.J. 1993. Equine bronchoalveolar lavage cytology: survey of thoroughbred racehorses in training. Aust. Vet. J. 70: 401-404. [Medline] [CrossRef]

22. McKane, S.A., and Slocombe, R.F. 2010. Experimental mild pulmonary inflammation promotes the development of exercise-induced pulmonary haemorrhage. Equine Vet. J. Suppl. 42: 235-239. [Medline] [CrossRef]

23. Michelotto, P.V. Jr., Muehlmann, L.A., Zanatta, A.L., Bieberbach, E.W.R., Kryczyk, M., Fernandes, L.C., and Nishiyama, A. 2011. Pulmonary inflammation due to exercise-induced pulmonary haemorrhage in Thoroughbred colts during race training. Vet. J. 190: e3-e6. [Medline] [CrossRef]

24. Michelotto, P.V. Jr., Lessa, D.A.B., Silva, K.M., Gawlowski, K.S.R., and Fernandes, W.R. 2013. The airway fluid analysis: methods and interpretation for the athletic horse. Rev. Bras. Cien. Vet. 20: 1-5.

25. Moran, G., Carillo, R., Campos, B., and Garcia, C. 2003. Endoscopic evaluation of exercise induced pulmonary hemorrhage in polo ponies. Arch. Med. Vet. 35: 109-113 [in Spanish].

26. Newton, J.R., and Wood, J.L. 2002. Evidence of an association between inflammatory airway disease and EIPH in young Thoroughbreds during training. Equine Vet. J. Suppl. 34: 417-424. [Medline] [CrossRef]

27. Otaka, J.N.P., Silva, K.M., Jorge, M.L., Gonçalves, C.A.P., Otaka, D.Y., and Lessa, D.A.B. 2014. Occurrence of pulmonary hemorrhage induced by exercise in polo horses in the city of Rio de Janeiro, R.J. Arch. Vet. Sci. 19: 46-51 (in Portuguese).

28. Pascoe, J.R., Ferraro, G.L., Cannon, J.H., Arthur, R.M., and Wheat, J.D. 1981. Exercise-induced pulmonary hemorrhage in racing thoroughbreds: a preliminary study. Am. J. Vet. Res. 42: 703-707. [Medline]
29. Robinson, N.E. 2003. Inflammatory airway disease: defining the syndrome. Conclusions of the Havemeyer Workshop. Equine Vet. Educ. 15: 61-63. [CrossRef]

30. Sad, E.P., Alencar, N.X., Viscardi, V., Costa, M.F.M., Hess, T.M., and Lessa, D.A.B. 2013. Cytology profile and age influence in the equine bronchoalveolar lavage in healthy and asymptomatic inflammatory airway disease. Cienc. Rural 43: 452-455. [CrossRef]

31. South African Polo Association. 2017. Beginner's Guide to Polo. http://www.sapolo.co.za/about/beginners-guideto-polo (accessed March 28, 2017).

32. Sullivan, S., and Hinchcliff, K. 2015. Update on exerciseinduced pulmonary hemorrhage. Vet. Clin. North Am. Equine Pract. 31: 187-198. [Medline] [CrossRef]

33. Sweeney, C.R., Humber, K.A., and Roby, K.A. 1992. Cytologic findings of tracheobronchial aspirates from 66 thoroughbred racehorses. Am. J. Vet. Res. 53: 1172-1175. [Medline]

34. West, J.B., and Mathieu-Costello, O. 1994. Stress failure of pulmonary capillaries as a mechanism for exercise induced pulmonary haemorrhage in the horse. Equine Vet. J. 26: 441-447. [Medline] [CrossRef]

35. Williams, K.J., Derksen, F.J., de Feijter-Rupp, H., Pannirselvam, R.R., Steel, C.M., and Robinson, N.E. 2008. Regional pulmonary veno-occlusion: a newly identified lesion of equine exercise-induced pulmonary hemorrhage. Vet. Pathol. 45: 316-326 [CrossRef]. [Medline]

36. Wood, J.L., Newton, J.R., Chanter, N., and Mumford, J.A. 2005. Inflammatory airway disease, nasal discharge and respiratory infections in young British racehorses. Equine Vet. J. 37: 236-242 [CrossRef]. [Medline]

37. Whitwell, K.E., and Greet, T.R.C. 1984. Collection and evaluation of tracheobronchial washes in the horse. Equine Vet. J. 16: 499-508. [Medline] [CrossRef]

38. Zinkl, J.G. 1992. Lower respiratory tract. pp.73-86. In: Diagnostic Cytology and Hematology of the Horse. 2nd ed. (Cowell, R.L., Tyler, R.D., eds.), Mosby, St. Louis. 